\title{
Elective surgical patients' narratives of hospitalization: The co-construction of safety
}

Carole Doherty $^{1}$ and Mark NK Saunders ${ }^{2}$

${ }^{1}$ Department of Health Care Management and Policy and ${ }^{2}$ Surrey Business School

Faculty of Business, Economics and Law

University of Surrey UK

c.doherty@surrey.ac.uk mark.saunders@surrey.ac.uk

This is a pre-publication earlier version of the following paper:

Doherty C and Saunders MNK (2013, online first) Elective surgical patients' narratives of hospitalization: The co-construction of safety and harm Social Science and Medicine

\begin{abstract}
This research explores how elective surgical patients make sense of their hospitalization experiences. We explore sensemaking using longitudinal narrative interviews $(n=72)$ with 38 patients undergoing elective surgical procedures between June 2010 and February 2011. We consider patients' narratives, the stories they tell of their prior expectations, and subsequent post-surgery experiences of their care in a United Kingdom (UK) hospital. An emergent pre-surgery theme is that of a paradoxical position in which they choose to make themselves vulnerable by agreeing to surgery to enhance their health, this necessitating trust of clinicians (doctors and nurses). To make sense of their situation, patients draw on technical (doctors' expert knowledge and skills), bureaucratic (National Health Service as a revered institution) and ideological (hospitals as places of safety), discourses. Post-operatively, themes of 'chaos' and 'suffering' emerge from the narratives of patients whose pre-surgery expectations (and trust) have been violated. Their stories tell of unmet expectations and of inability to make shared sense of experiences with clinicians who are responsible for their care. We add to knowledge of how patients play a critical part in the co-construction of safety by demonstrating how patient-clinician intersubjectivity contributes to the type of harm that patients describe. Our results suggest that approaches to enhancing patients' safety will be limited if they fail to reflect patients'
\end{abstract}


involvement in the negotiated process of healthcare. We also provide further evidence of the contribution narrative inquiry can make to patient safety.

\section{Keywords}

\section{UK; patients' stories; patient safety; sensemaking; trust; hospital}

\section{Introduction}

In this paper we explore how elective surgical patients make sense of their hospitalization experiences and how that sensemaking shapes and re-shapes their understanding of safety, through the stories they tell. Stories or narratives are accounts of events, 'verbal utterances occurring in space and time' (Chia, 2000:p513). They are the manner in which people make sense of the world and their part in it and can serve as moral tales, giving the listener insight as to how the narrator thinks the world should be (Frank, 2000; Riessman, 1993). In the healthcare context patients' stories are a means to obtain information about illness, and offer a method by which practitioners can gain a deeper, subjective understanding of patients' experiences (Fear, 2013). They can facilitate reflection on, and refinement of, professional roles and responsibilities (Greenhalgh, Russell \& Swinglehurst, 2005), and assist clinicians to learn from events which resulted in patient harm (Iedema, Jorm \& Lum, 2009).

Our paper begins by examining how sensemaking is a 'discursively constituted' (Iedema, 2011: p1168) process and examines how everyday discourses are shaped and informed by Paradigm-type Discourses (Alvesson \& Karreman, 2011:p1129), which limit the frames of reference people use to make sense of events (Weick, 1995). Next, we consider patient safety and trust. Then we detail our method outlining the research setting and design. Following this, we consider how in the preoperative period, patients make sense of their initial decision to have an operation, which places them in a paradoxical position, their narratives expressing a 'shifting dialectic of trust and doubt' (Williams \& Calnan, 1996: p1613). We then explore patients' stories of their post-operative experiences when, having put their trust in clinicians, for many their expectations are violated. Finally, we consider the 
implications of our findings for patient safety.

\section{Sensemaking, Storytelling and Discourse}

Humans think and interact in narrative (Fisher, 1984), developing shared meanings and corresponding forms of action by the use of language and the telling and retelling of stories (Weick, 1995). As abridged versions of events, narratives may or may not reflect actual experiences (Alvesson, 2003). Rather, they describe the narrator's interpretations of her/his experiences and the meanings $\mathrm{s} / \mathrm{he}$ attributes to them. Meaning and coherence or sensemaking of the world occurs through people's telling and retelling of their particular versions of events. How people understand events comes to take the form of the stories they tell, these informing their understanding of their own beliefs and situation (Fisher, 1984; Weick, 1995).

In situations of uncertainty, sensemaking becomes a crucial process in the attempt to create order from disorder. Using cues to notice and bracket events, people place the unfamiliar into known categories pigeon-holing or labelling, to generate provisional, plausible, negotiated narratives (Weick, 1995). This process involves the co-construction of reality by intersubjective linguistic interaction, or 'small d' type discourse, where 'language is used to accomplish things in a highly localized setting' (Alvesson \& Karreman, 2011: p1140). It occurs in a manner that predisposes people to notice, acknowledge and question some things, but bracket out others (Iedema, 2011; Weick, 1995). Such noticing and bracketing are guided by mental models. These include individuals' sense of identity and belonging to particular social or organizational groupings, their previous experience, knowledge and beliefs (Brown, Stackey, \& Nandhakumar, 2008; Weick, 1995). Consequently, individuals tell their stories using language designed to preserve their self-esteem and social legitimacy, their narrative sensemaking tending to construct a version of events that is critical of others while placing themselves in a positive light (Brown, 1998; Brown \& Humphreys, 2003).

Sensemaking frames of reference are also located in 'Paradigm-type Discourses' or 'meta-discourses' (Alvesson \& Karreman, 2011; Iedema, Flabouris, Grant, \& Jorm, 2006). Such Paradigm-type Discourses or 'big D', distinct from the 'small d' type discourses of everyday conversation (Alvesson 
\& Karreman, 2011), are informed by bodies of knowledge and are particular to standardized sociocultural ideas of any given period. As such, Paradigm-type Discourses offer legitimization and authorization of dominant ideas, presenting them as truths (Syrjälä, Takala \& Sintonen, 2009). Discourse in this sense conveys the relationship between power and knowledge: in the intersubjective construction of knowledge, the frameworks that Paradigm-type Discourses provide for organizational actors' sensemaking reflexively privilege the position of some actors over others, producing 'the silencing effect of power discrepancies' (Edmonson, 2003:p1444). At the intersubjective level, 'small d' discourses used by those who are less powerful to mediate meanings and make sense of reality, are likely to be judged less plausible within the Paradigm-type Discourse of those in positions of power which may lead them to dismiss differences in other's accounts (Boje, 1995; Vickers, 2008). This suggests that the discourses patients use to make sense of their treatment may differ from those of clinicians. Nonetheless, patients' sensemaking, and subsequent decision-making, will be influenced by the clinicians' sensegiving that is located in, and arises from, the stories that clinicians tell patients about events and the socially constructed meanings they ascribe to them (Maitlis \& Lawrence, 2007).

Within healthcare, intersubjective meanings are framed within the habituated and generic subjective meanings, embodied in rules and procedures of the organization and the knowledge and practice of the healthcare professions (Hales, 2007). In this context, the discursive power of modern medicine's scientific objectivity has repressed subjective, emotional and moral aspects of the patients' experience (Frank, 1997; Islam \& Zyphur, 2007). Patients' discourses may be polyphonic but it is the medical Paradigm-type Discourse that is the dominant story or 'regime of truth' (Brown, 1990: p192) against which the others are judged (Frank, 1997). In their analysis of the paediatric heart surgery scandal at the UK's Bristol Royal Infirmary, Weick and Sutcliffe (2003) argued that the unwillingness of clinicians, such as nurses, to challenge unsafe practice arose from occupational and organizational cultural norms. These norms embedded surgeons at the top of the institutional hierarchy because of their assumed expert knowledge and the clinical autonomy which that warranted. Hence, we assume that there is a recursive dynamic between Paradigm-type Discourses ('big D') and every day discourses ('small d') (Iedema, 2011) which may reduce an organization's capacity to function safely 
by legitimizing a dominant group's worldview, limiting people's understanding of the organization's complexity and their wariness for the myriad ways in which things can go wrong (Weick, 1988; 1993).

At an institutional level the UK National Health Service (NHS) has a unique historic combination of professional and managerial bureaucracy (Clark \& Newman, 2006). It has been mythologized as a theological institution, a national religion shaping, and symbolic of, shared values of human dignity, equality and trust (Klein, 2006; Neuberger, 1999). Since the 1980s, the NHS has been subjected to continuous government inspired change. The medical Paradigm-type Discourse has been challenged by another Paradigm-type Discourse; that of managerial efficiency, where clinicians are criticized as conservative, self-interested and profligate in their use of resources (DH, 2010). In this particular version of events, with economic constraints and an ever increasing demand, hospitals are exhorted to do 'much more for less' (Audit Commission, 2010:p3); efficiency prevailing over safety. With such pressure on front-line employees, often from senior managers, the violation of procedures appears to be endorsed as a means of increasing productivity and coping with competing demands. Over time such violations become routinized, resulting in the 'normalization of deviance' (Amalberti et al., 2006:i69). It is within this context that some clinicians may behave carelessly and cause patient harm (Amalberti et al., 2006; Weick \& Sutcliffe, 2003).

\section{Patient safety and trust}

Efforts to advance patient safety have attended to reducing risks from unsafe acts and hazardous systems, drawing lessons from aviation and the nuclear industry which are considered to have safe systems (Hudson, 2003). Consequently, the focus has been on rule-based approaches to improvement: checklists, utilizing protocols and implementing incident reporting systems (Ocloo, 2010; Waring, 2009). However, such industry based models do not reflect the patients' unique involvement in healthcare, safety research leaving the patients' perspectives relatively unexplored (Jorm et al., 2009). Rather, in accordance with theory of presumptive trust (Kramer, 1999), the current approach to patient safety and safe systems in healthcare, appears to consider trust as being created and sustained through 
'managerial relationships, accountability, and credibility' rather than interactions between healthcare professionals and their patients (Brown, 2008:p352). Within this it is not the individual whom is trusted, but the system of expert knowledge that produces and maintains that person in the role (Meyerson, Weick \& Kramer, 1996). Indeed, clinicians' expertise is held in high esteem by patients (Lloyd, 2001), many of whom may believe that their role is one of passive recipient (Doherty \& Stavropoulou, 2012). Patients' trust judgements, and associated willingness to make themselves vulnerable to clinicians in the expectation they will be safe, are therefore likely to be based upon inferences regarding the trustees' ability (relevant skills and competence), benevolence (caring orientation) and integrity (honesty and fairness) (Mayer, Davis \& Schoorman, 1995).

Patient safety groups have become increasingly vocal, with campaigns to encourage and empower patients to 'speak up' if they have questions or concerns about their care (JCAHO, 2011). Although many patients may be willing and able to monitor and protect their safety, success of their efforts is crucially dependent on clinicians' willingness to listen and act on the patients' concerns (Hor et al., 2013). Waring (2009) demonstrates how the construction of safety and harm in healthcare is contested terrain where, by intersubjective processes, knowledge is constructed and re-constructed to serve the interests of the various managerial and clinical stakeholders. Similarly, Jorm et al. (2009) argue that, while clinicians may prioritize physical harm, patients are likely to report both physical and psychological harm including poor or insensitive communication. Barriers to patients' active involvement in error reduction include lack of information, beliefs about self-efficacy in respect of preventing errors and clinicians appearing too busy. The most important are illness and patients' perceptions of their role and status as subordinate to that of clinicians (Doherty \& Stavropoulou, 2012).

To investigate patients' sensemaking narratives of their hospitalization experiences we selected a sample of elective surgical patients. Through exploring how their narratives are constructed and reconstructed before and after surgery we illustrate how patients make sense of their hospitalization and how that sensemaking shapes and re-shapes their understanding of safety. 


\section{Method}

\section{Research setting}

Our study was conducted in a district general hospital in the South West of England between July 2010 and February 2011. At the time of data collection, stories regarding hospital safety had become prominent in the national media following investigations into the poor quality of care at a number of English hospitals (Healthcare Commission, 2006, 2007, 2009). Throughout the research period, the hospital's performance was, like 60 per cent of other district hospitals, rated as 'intermediate'. (CQC, 2010). The context of our research was the sensemaking of patients who require elective surgery. All such patients first attend a pre-operative assessment clinic. At this stage they are given written and verbal information about their treatment and give consent for surgery. On the day of surgery patients are again examined by clinicians, before going to theatre. Following surgery patients are transferred to a ward where they stay until discharged home.

\section{Research design}

Our research design was longitudinal, contextual and processual and involved being engrossed in the 'flowing soup' (Weick, 1995:p128) of organizational events in an inductive effort to construct thick description (Geertz, 1973) regarding how patients make sense of their hospital treatment. Following ethical approval from the Local NHS Research and Ethics Committee, data were collected using preoperative and post-operative (in-hospital and post-discharge) narrative interviews, supplemented by documents such as patient information leaflets. Obtaining patients' narratives at these stages of their treatment ensured the chronological connections and the temporal sequencing of events were preserved (DeFina \& Georgakopoulou, 2008). It also allowed insights into possible changes in their intersubjective experiences; an aspect that researchers in other contexts indicate would be difficult to gain through other methods (Syrjälä, Takala \& Sintonen, 2009).

Patients preparing for planned surgical procedures were recruited initially by nursing staff, when they attended their pre-operative assessment visit. As a consequence they were likely to be both prepared 
and informed about their treatment and therefore more able to make sense of events than those admitted for emergency care. Willing patients were subsequently contacted over an eight month period and a maximum variation purposive sample (Saunders, 2012) of 40 selected from all those undergoing elective surgery, involving at least one night's stay, 38 consenting to take part. Surgery included procedures to address both chronic disease and acute short term problems, thereby allowing key themes across a range of treatments to be revealed (Saunders, 2012). We also sought to select patients of varying ages, any patterns that emerged being likely to be of wider interest and value (Patton, 2002). Each patient was identified by a code comprising, their gender $(\mathrm{M}=$ male, $\mathrm{F}=$ female $)$ and age in years, patients of the same gender and age being differentiated by second alphabetic character. Participants comprised 13 males and 25 females aged between 24 and 89 years, with a mean age of 61 years, this being similar to the UK adult hospital population (The Information Centre, 2010). 72 narrative interviews (Table 1) were undertaken to explore these patients' experiences of the system and to facilitate understanding of the processes by which they made sense.

\section{Table 1: Patient interviews}

\begin{tabular}{|c|c|c|c|c|c|}
\hline \multicolumn{3}{|c|}{ Stage at which interview conducted } & \multirow{3}{*}{$\begin{array}{l}\text { Number of } \\
\text { interviews } \\
\text { per patient }\end{array}$} & \multirow{3}{*}{$\begin{array}{c}\text { Number of } \\
\text { patients }\end{array}$} & \multirow{3}{*}{$\begin{array}{c}\text { Total } \\
\text { number of } \\
\text { interviews }\end{array}$} \\
\hline \multirow{2}{*}{$\begin{array}{c}\text { Pre- } \\
\text { operative }\end{array}$} & \multicolumn{2}{|c|}{ Post-operative } & & & \\
\hline & In hospital & $\begin{array}{c}\text { Post } \\
\text { discharge }\end{array}$ & & & \\
\hline$\checkmark$ & $\checkmark$ & $\sqrt{ }$ & 3 & 6 & 18 \\
\hline$\checkmark$ & $x$ & $\checkmark$ & 2 & 22 & 44 \\
\hline$\checkmark$ & $x$ & $x$ & 1 & 10 & 10 \\
\hline Total & & & & 38 & 72 \\
\hline
\end{tabular}

38 pre-operative interviews were conducted face-to-face in a private office in the hospital and audio recorded. The purpose of the research was explained and each participant reassured that the researcher was not employed by the hospital. Patients were asked to tell their stories about previous experience of healthcare and the expectations they held about their forthcoming surgery. During interviews a relaxed tone was set, questions allowing lines of inquiry to be followed as the patient's narrative developed. Four patients were accompanied by relatives who added to the narrative confirming the 
story and offering their version of events when prompted by the respective participants. These interviews lasted between 10 minutes and one hour. 10 patients were only interviewed once (before surgery), attrition being due to surgery cancellation (2), patient moving away from the area (1), had enough of hospitals and do not want to think about it again (1) and being unable to make contact postdischarge (6).

Post-operation six patients with lengths of stay greater than five days undertook a second audio recorded face-to-face interview in hospital, lasting between 60 to 90 minutes, and a post-discharge telephone interview. A further 22 patients undertook the post-discharge telephone interview within four weeks of discharge. Post-discharge telephone interviews were between 10 to 50 minutes duration. Patients were asked to describe their experience of being in hospital, events in the immediate post-discharge period and any concerns they had about their safety. Prompt questions relating to the patient's story, derived from Labov's (1997) model of natural narrative structure, were used. For example the questions: 'What did you say or do?', 'Why did you act in that way?' and 'What happened then?' were used to prompt the core narrative element. The question 'How do you feel now?' was used to help make the point of the story clear. Following Gabriel (1999) ambiguities within patients' narratives were accepted, these being likely to result from ambivalent feelings, unclear understanding or lack of knowledge. Contemporaneous notes made during telephone interviews were transcribed immediately afterwards.

In analysing these data we recognize that stories are constructed firstly by the patient narrator and, then again by us as researchers. Consequently we become the spokespeople for others, reconstructing their stories and in doing so imposing theoretical categories aimed at providing our particular audience with 'an intuitively convincing account' (Bruner, 1991:p7). Important in this respect is our experiential knowledge as researchers, which invariably influences our interpretation of the story. The lead researcher is a nurse with over 25 years of experience working in the NHS; the other has considerable experience of researching social care. Invariably our understandings are reflected in the co-construction of these patients' stories. Our patients' stories are not complete but terse narratives; 
shortened versions of events in which there are other characters and different stories to be told (Boje, 1991). As such we consider they offer individuals' versions of reality whose acceptability is likely to be governed by conventions such as their deference to authority rather than by empirical verification and logical requiredness (Bruner, 1991). Each patient's set of narratives offers a unique unfolding 'emplotment' (Syrjälä, Takala, \& Sintonen, 2009:p268) comprising connected sequential events relating to their experiences of their hospitalization.

\section{Figure 1. Data analysis}

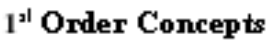

2w Order Themes

Aggregate

Dimensions

- Symptoms will reduce
- More mobility
- Getting out of this operation successfully

Plausible stories of

anticipated outcomes

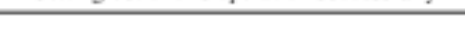

\begin{tabular}{|c|}
\hline $\begin{array}{l}\text { - Fecling very vulnerable } \\
\text { - Scary }\end{array}$ \\
\hline $\begin{array}{l}\text { - Confidence in National Health Service } \\
\text { - Safe in bospital } \\
\text { - Fantastic surgeons }\end{array}$ \\
\hline
\end{tabular}

High Arousal/Negative emotions
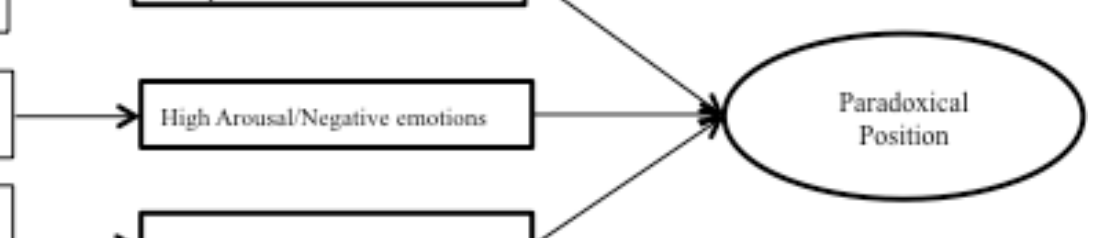

Trust

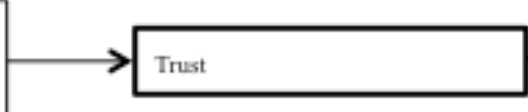

\section{- Come in for [his] surgical skills \\ - Use of technical skills \\ - [Patient] not knowledgeable}

- Situation is beyond my control

- Do as [1 am] told

- On the receiving end

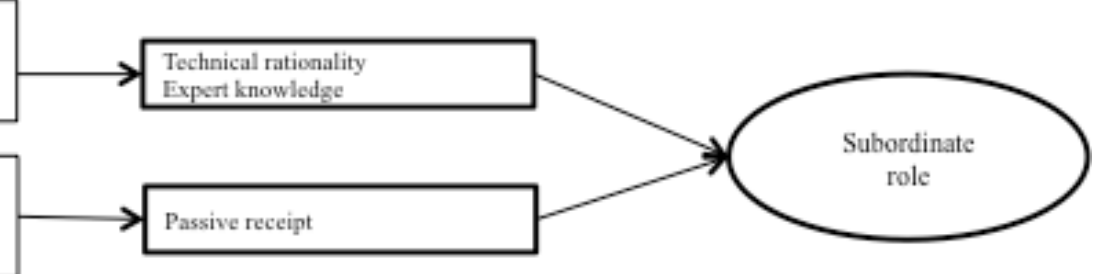

\section{- Isolation \\ - Nothing was done \\ - Strange place, quite bizarre \\ - Confusion}

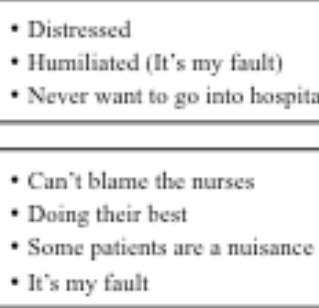

- Can't blame the nurses

- Doing their best

- Some patients are a nuisance

- It's my fault

Our analysis followed the approach recommended by Corley and Gioia (2004) identifying first order concepts, grouping these as second order themes and searching for explanatory aggregated dimensions. Within each patient's account we identified first order concepts and grouped them into categories using open coding (Corbin \& Strauss, 2008) searching for conditions, interactions among 
actors, strategies, tactics and consequences. Participants' own words or 'in vivo' codes were used where possible resulting in first order concepts such as 'symptoms will reduce' and 'more mobility' (Figure 1). We then undertook axial coding searching for relationships between and among the initial concepts. These became our second order themes, for example the concepts referred to earlier were categorised as 'plausible stories of anticipated outcomes'. This was an iterative process involving constantly comparing accounts to select and reduce the data to a core set of (second order) themes by merger and delimitation and searching for confirming and disconfirming evidence as possible explanations emerged (Corbin \& Straus, 2008). For example, it emerged that the second order themes 'Plausible stories of anticipated outcomes' and 'High arousal-negative emotions' along with 'Trust' were explained by 'paradoxical position'. Whilst an explanation for the second order themes of 'Chaos', 'Suffering' and 'Search for meaning' was 'Trust violation'. These became our 'aggregate dimensions'.

Next, we discuss the themes and explanatory aggregate dimensions which emerged from our analysis of the pre- and post-operative stages, taking into consideration patients' and clinicians' relative positions and associated power.

\section{Sensemaking in the pre-operative period - paradoxical positions and subordinate roles}

The initial decision - a paradoxical position

Patients make sense of their forthcoming surgery, expecting it to enhance their health. Providing consent to surgery necessitates a trust judgement, the associated vulnerability simultaneously engendering high arousal and negative emotions. This is 'scary' because it threatens their identity as autonomous adults, 'your life potentially is the hands of somebody else' (F24), and engenders fear over their forthcoming vulnerability and dependence on others for one's basic needs. To justify and remain committed to their course of action, patients make prospective sense of their decision with plausible stories about anticipated outcomes: '[ $\mathrm{I}$ am $]$ a bit apprehensive about the operation... but after I hope the symptoms will reduce dramatically' (M63a). Faith is instrumental to sensemaking (Weick, 1995) and patients expect that 'they won't [go wrong] with us' (M75a). Despite an awareness of media reports to the contrary, they create a plausible story about the 'fantastic' surgeons' and the 
'brilliant' nurses' who are part of a shared referent: the institution of the UK NHS 'a cocoon from the outside world' (M38) in which they 'have total faith' (F63) and feel safe. Patients can have a poor understanding and memory of information related to treatment risks. Such denial of risks can be considered adaptive behaviour because it helps reduce the emotive impact of illness. Accordingly, patients typically hold doctors in high esteem (Lloyd, 2001).

At the pre-operative stage patients said they trusted the technical competence (abilities) of the clinicians, often basing this presumptive trust on knowledge of family or friends who are clinicians, on previous hospital experience or their own lack of expert knowledge:

I have every confidence that the NHS will function in the way it should when they do my knees. I have very, very little respect for the press in this country. (M75a)

I don't have private health insurance. I have paid towards the NHS all my life and, on principle, I would not seek private healthcare. If anything really goes wrong there is only one place to be, that is the NHS. (M68)

I've known some friends who are medics. I'm conscious of the depth of training they have been through and that it's at the sharp end, hospital treatments. (F74)

Their narratives draw on technical (doctors' expert knowledge and skills), bureaucratic (NHS as a revered institution) and ideological (hospitals as caring places of safety) Paradigm-type Discourses as justifications for their trust (Fisher, 1984). They suggest that patients find comfort in modernist cultural assumptions of the restorative powers of medicine and hospitals (Frank, 1997).

\section{Subordinate role}


Pre-operative patients' stories suggest an acceptance of a new, albeit temporary, identity as a patient. They appear willing to make themselves vulnerable, trusting the technical rationality of medicine, discharging their own personal responsibility and accepting the authority of clinicians.

I'm sure it'll all happen, and I'll be told what to do and I will probably do it and when they say 'You can go home' I will go home. (M38)

As non-experts, patients perceive they are passive recipients in a hierarchical system where they are not qualified to judge (Weick \& Browning, 1986), arguing 'a lay man cannot question doctors' (M 75b). Although central to the organization's purpose, patients present themselves by contrast to clinicians as: passive rather than active; ignorant as opposed to knowledgeable; inferior rather than superior; and as information receivers rather than information transmitters.

I'm not knowledgeable on drugs and hopefully they are. (M53)

You feel inferior to a doctor or a nurse. (F56b)

In so doing, they often select and interpret sensory experiences, such as clinicians' behaviour, in a manner that confirms their assumed subordinate status and as an object of medical expertise.

The consultant never spoke to me once. When I went into theatre Mr [surgeon's name] was on my left hand side, he did not say good evening or sorry to keep you waiting. It is routine for them, they must get fed up with it, I suppose. It makes you feel that you are beneath him. (F56a)

In describing her feelings in the operating theatre immediately prior to a previous operation this patient's story reveals how the surgeon's non-verbal behaviour suggests clear guidance about social norms (Alvesson \& Karreman, 2011). Other patients describe their resistance to more active 
involvement when, in contrast to the aforementioned surgeon, clinicians attempt to involve patients in pre-surgery decision-making.

The anaesthetist asked me which was my preference, of anaesthesia ... I don't know which is better. So I asked him, 'What would you suggest?'... and he gave his opinion which I accepted. There's no way I know whether a mask on your face or a needle in your arm or one up your backside, whatever, I have no idea! (M67)

Patients appear to construct their role in the process of care delivery from their assumptions about social norms and the interpretive frameworks they use to make sense of events. Prior to surgery, apparent passiveness and presumptive trust based on trustees' abilities, serve to reinforce the dominance of the professions in the hierarchical organizational structure. Expectations of expert knowledge serve to comfort and reassure them; their sensemaking emphasizing technical rationality. This suggests collusion in the reproduction of the institutional order, conformance to third order controls (Lukes, 2005) and constraint of their personal agency (Green \& Li, 2011).

\section{Sensemaking in the post-operative period -trust violation}

For some patients, post-operative recovery is much as anticipated; but many describe how clinicians' behaviours are not as they expected, particularly regarding benevolence. Two themes emerging from these patients' pre and post-operative narratives support Franks' (1997) 'chaos' narrative - a loss of control and inability to make shared sense of their predicament with the clinicians, who are responsible for their care and isolation; and his 'suffering' narrative - 'opposition of the minds message of care and the body's message of pain' (p173). The third theme is patients' 'search for meaning' to restore their trust in the clinicians.

In the post-operative period patients' dependency on clinicians, particularly nurses, increases alongside the potential for trust violation. For many this appears to be when their pre-operative narratives begin not to make sense; their anticipated positive outcomes and the expectation of 
benevolent care whilst vulnerable, becoming more ambiguous. For many patients their trust in the technical competence of clinicians, within a bureaucratic safe house, appears misplaced as they describe pain that is poorly managed, requests for assistance unanswered and basic physical needs often under met.

There were a lot of older men that couldn't get out of bed by themselves or needed help. When they asked for bottles the nurses said in a minute. Sometimes the bottles would arrive but sometimes not. One old man was so desperate he had two bottles but they were full up. He poured one of them into the water jug. (M63)

I was given morphine even though I told them I was allergic to morphine, ...it must be the epidural had morphine in it. ... The anaesthetist, when I told him that I was allergic to morphine he said 'they are just side effects' and got on with it. I said I don't want it. He gave me that epidural anyway. The bed was careering down the ward; I was terrified to close my eyes. (F84)

This 84 year old woman, whose son and grandson were both doctors, was delighted pre-surgery to have the surgeon of her choosing. However, post-operation she felt that she had suffered needlessly because of the actions of the anaesthetist.

'A side effect is a side effect but they are not the patient... In the end I said, 'I can't argue with you as you are the experts'. (F84)

A consultant anaesthetist confirmed that epidurals do not contain morphine. This patient's story illustrates a tendency for clinicians to reduce the density of illness experience to technical abstraction (Iedema, 2009). What is important to this patient is her perception that she received morphine. These experiences violate patients' prior categories, their sensemaking frameworks and their trust. Confronted with their subjective experience and unmet expectations of expert and benevolent 
treatment, previously anticipated outcomes become more ambiguous and judgements of trustworthiness are reduced. Patients' narratives now focus on their unmet expectations of being cared for. They struggle to make sense of events, no longer seeing their own narratives as plausible because they find that they are powerless to articulate their personal, body-related knowledge using language which makes it relevant to the clinicians.

Unable to bring order to their unstable embodied experiences, and transform the unfamiliar into familiar categories, through reaching shared meaning and agreed actions with those clinicians caring for them, patients often express a loss of control and describe becoming 'meek in the face of authority' (F77).

I was quite ill as well ...I did tell them that I couldn't see properly, they just sort of said things like 'Oh well it could be all the medication and everything' ...I actually felt that they thought I was being a bit of a nuisance and I was quite upset about that. That's why I accepted that and didn't ask until my visit to outpatients ... they did an MRI scan and that was when it was confirmed that I had had a stroke. (F58)

As the above quote from a woman who had a knee joint replacement demonstrates, diminished intersubjective perceptions of what is going on, creating misunderstandings between patients and clinicians appear to cause both physical and psychological harm to patients. In a post-discharge interview, a urology patient explained how, on the day following surgery, he had been told by his surgeon that the urinary catheter, inserted during surgery, could be removed. Neither the patient nor the attending nurse believed this to be appropriate, but did not question the decision.

She [the nurse] said "I can't go against what he says". If the nurses won't question the consultant then how can I? He looked like he was off to play golf...He had funny jumpers and stuff and he couldn't get out [of] there quick enough.' (M46) 
Over the following days this patient had a total of four catheters re-inserted as he was unable to pass urine. During this time he felt that his views and concerns had been ignored, questioning both the ability and benevolence of clinicians involved:

I had a [urinary] catheter in. He [surgeon] didn't look at it; he said that's fine you'll be out today. The nurse thought it was too soon to take it out. Anyway she took it out...by the afternoon I tried three times [to pass urine] but couldn't manage. It was agony. The nurse came and shoved a catheter into me. The next morning the doctor said take it out, by Saturday evening I was having spasms and was in agony so another one was put in and I waited another day. All told the catheter was in for 3 weeks, all because they took it out too soon. (M46)

Another recalled her experience of using a patient controlled analgesia machine. Before using the device she had been concerned but was reassured by the nurses that nothing would go wrong. However, she soon began to have frightening hallucinations:

I didn't understand what was going on,.. I said I was hallucinating to the nurses, they did absolutely nothing about it at all ...I called the police, this is because I was nuts though, and said they [nurses] were trying to kill me. The staff nurse yelled and screamed at me, dragged me into another room with another nurse, telling me off horribly while I was sobbing. I said I wanted to go home, they said, 'You can't' and they put me in another ward overnight... they never came back to see me. (F55)

Patients' inchoate narratives tell of confusion and isolation as they struggle for meaning and to make sense of their experienced realities. They are 'puzzled' by the lack of communication and explanation from clinicians, and describe feeling 'shocked' and 'traumatized', believing that nothing is being done. Their stories describe high levels of negative emotions: 'distress', 'anxiety' and 'fear'. 
I would have happily shot myself if there was a gun in the room. (M63a)

They attempt to normalize the situation and maintain trust by blaming themselves when confronted with experiences that contradict their prior assumptions about the benevolent staff and safety of hospitals:

Codeine...[makes] me violently sick, frightened and dizzy. What really baffled me was that I had told the nurse that I couldn't take codeine but the same nurse, I could hear her saying she can take codeine. ... maybe it was a good thing for me to be sick. (F77)

Organizational constraints, in particular staff shortages, are offered as plausible explanations for events. Patients' narratives describe how, 'There were not many nurses on, they were always busy' (M67a) dealing with multiple demands from those people who are worse off, such as 'One old boy [who] fell out of bed' (M40). Their stories attempt to counteract feelings of self-doubt by social comparison and impression management. Their storytelling distances them from 'difficult' patients who were 'a wretched nuisance' (F84), and present a positive narrative about helping the nurses, and being 'good' patients, not being 'a moaner', 'a complainer' or 'a nuisance', supporting Doherty and Stavropoulou's (2012) conclusion that patients avoid conflict with clinicians as they fear being labelled as 'difficult'.

Patients say that they are unwilling to complain about their bad experiences because: they suppose that nothing will change; they require further treatment and believe that if they complain they will be penalized, suggesting a loss of trust in staff integrity; or they have no desire to relive or prolong the experience.

\section{Discussion}


In anticipation of their forthcoming surgery, patients' in this study tell seemingly contradictory stories in which they claim to trust the abilities of clinicians, feel safe and confident of the outcome whilst also expressing low pleasure emotions such as feeling scared and vulnerable. This places them in a paradoxical position of feeling vulnerable while claiming to feel safe. To make sense of their predicament, their stories draw principally on ideological, bureaucratic and technical Paradigm-type Discourses to justify trust in clinicians and to construct a positive future in which they have better health. In this environment, where patients feel exposed and uncertain they need to trust that clinicians will do them no harm. Hospitals have distinct patterns of hierarchical authority, influenced by the power and exclusivity of medical knowledge and, at least in the public sector, by a managerial context which valorises efficiency. Patients in this study generally constructed themselves in a subordinate trusting role, where they should follow the rules laid down by clinicians, the people they believe are the most qualified to make the decisions because they have the requisite technical knowledge.

To make sense of clinical data by transforming it into organized activity and to manage within available resources, clinicians pigeonhole patients into diagnostic categories in predetermined situations (Weick, Sutcliffe \& Obstfeld, 2005). For clinicians there may be few surprises to be made sense of in their daily work routines. In contrast, patients' narratives describe their unusual and emotional experience of physical illness, pain and dependency. Patients tell how clinicians, who often seem to be under time pressure, ignore, misinterpret or underestimate their visceral experiences.

In this situation, there appears to be discrepant intersubjective sensemaking. Patients describe a chaotic experience, which on occasions can engender both physical and psychological harm. They feel isolated and without emotional support or understandable explanations for some events. They perceive the organization as turning against them (Munro \& Huber, 2012). It becomes a 'weird prison' (F55) and their trust in it as a benevolent place of safety is breached. Where patients lose trust in the ability and integrity of clinicians, their fear is likely to increase as their sensemaking fails. The sense of humiliation and trauma they express is rooted in the social distance and unequal knowledge 
inherent in clinician-patient relationships. Patients and clinicians each have their own cognitive maps, thus misinterpretation abounds and each misunderstanding is compounded by, and embedded in, attempts to communicate (Munro \& Huber, 2012). When they find their pre-surgery expectations violated, patients struggle, within their passive and subordinate role, to make sense of their situation, their narratives suggesting a sense of loss of control and self-blame. Our results support Weick's (1993) assertion that there is a safety triangle of trust, self-esteem and honesty (integrity) and when this is broken there is greater fear, less communication and greater risk of injury or death. To reduce fear (and maintain trust) people have to make sense of what is happening. Accordingly, patients in our study make excuses to mitigate any negative inferences that could be attributed to clinicians' actions and, in so doing, they can become caught in discourses of self-blame and disempowerment. Nonetheless, their discourses serve to justify and preserve their prior confidence in both the NHS as an institution and the expert knowledge of the medical profession, their reflexive narratives returning them to, and reinforcing, their initial paradoxical position of trust and doubt, certainty and uncertainty, reverence and disillusionment (Williams \& Calnan, 1996).

In some instances, when a crisis is encountered within the organization, for example a patient suffering an anaphylactic reaction, rather than created by the organization (See Weick, 1988), fast efficient action requires restricted sensemaking and autocratic decision making (Brooks \& Bosk, 2013). More often guided sensemaking (Maitlis, 2005) is necessary to enable shared understanding and more reliable decision making. This requires clinicians to show benevolence, to listen to patients' accounts and to involve patients in explanations of processes. When clinicians fail to assimilate patients' interpretation of events, as illustrated by the patients' narratives, the variety of cues available to them may reduce their sensemaking, restricting their capacity to understand the situation with negative consequences for decision making and patient safety.

\section{Conclusion}

Our paper investigated elective surgical patients' sensemaking of their experience of hospitalization. The nature of our study means generalizations we can make are invariably theoretical, relating to 
elective surgery patients within intermediately performing UK general hospitals. Further research is needed in diverse contexts and with different groups of patients. Nonetheless, our results are an important addition to the literature on patient safety. They reveal how patients draw on ideological, bureaucratic and technical Paradigm-type Discourses to make sense of their forthcoming surgery. When, in the post-operative period, patients perceive that clinicians are dismissive of their concerns, these prior sensemaking categories are violated. Contrary to findings from other studies in different contexts, rather than sensemaking by scapegoating and creating excuses to preserve their self-esteem (Brown, 1998; Brown \& Humphreys, 2003), we show how patients can become caught in discourses of self-blame, unfamiliarity and disempowerment which can result in psychological and on occasions physical harm.

Healthcare is unique in respect of its intersubjective dimensions (Reason, 2008). Approaches to improving safety, which focus on implementing incident reporting systems, checklists and protocols, fail to address the patients' part in the negotiated process of healthcare and the importance of clinicians' benevolence in maintaining trust within the social-cultural context in which care takes place. Our results add further evidence to calls for the development of healthcare specific, rather than industry derived, approaches to inform and improve patient safety which embrace the patients' involvement in the negotiated process of healthcare (Hor, Godbold \& Iedema, 2013; Jorm, et al., 2009).

\section{References}

Almaberti, R., Vincent, C., Y. Auroy, Y. \& de Saint. Maurice, G. (2006). Violations and migrations in health care: a framework for understanding and management Quality and Safety in Health Care, 15(suppl):i66-i71

Alvesson, M. (2003). Postmodernism and Social Research. Open University Press: Great Britain Alvesson, M. \& Karreman, D. (2011). Decolonializing discourse: Critical reflections on organizational discourse analysis. Human Relations, 64(9), 1121-1146 
Audit Commission. (2010). Delivering More for Less. Audit Commission: London.

Boje, D.M. (1995). Stories of the storytelling organization: a postmodern analysis of Disney's

“Tamara-land". Academy of Management Journal, 38(4), 997-1035.

Boje, D.M. (1991). The storytelling organization: A study of story performance in an office supply firm. Administrative Science Quarterly, 36(1), 106-126.

Brooks, J.V. \& Bosk, C.L. (2013). Bullying is a systems problem. Social Science \& Medicine, 77, 1112.

Brown, A.D. (1998). Narrative, politics and legitimacy in an IT implementation. Journal of Management Studies, 35(1),35-58.

Brown, A.D. \& Humphreys, M. (2003). Epic and Tragic Tales: Making Sense of Change. The Journal of Applied Behavioral Science 39(2),121-144.

Brown, A.D., Stackey, P. \& Nandhakumar, J. (2008). Making sense of sensemaking narratives. Human Relations, 61(8), 1035-1062.

Brown, P. (2008). Trusting in the new NHS: Instrumental v. communicative action. Sociology of Health \& Illness, 30(3), 349-363.

Brown, R.H. (1990). Rhetoric, Textuality, and the Postmodern Turn in Sociological Theory. Sociological Theory, 8(2), 188-197.

Bruner, J. (1991). The Narrative Construction of Reality. Critical Inquiry, 18(1), 1-21.

Chia, R. (2000). Discourse Analysis as Organizational Analysis, Organization, 7(3), 513-18.

Clarke, J. \& Newman, J. (2006). The Managerial State. Power, Politics and Ideology in the Remaking of Social Welfare. London: SAGE. ( $5^{\text {th }}$ Edn.).

Corbin, J.M. \& Strauss, A.L. (2008). Basics of Qualitative Research: Techniques and Procedures for Developing Grounded Theory. London: SAGE.

Corley, G.K. \& Gioia, A.D. (2004). Identity Ambiguity and Change in the Wake of a Corporate Spinoff. Administrative Science Quarterly, 49, 173-208.

CQC. (2010). Care Quality Commission NHS Performance ratings. http://www.cqc.org.uk accessed $6^{\text {th }}$ Oct 2012. 
DeFina, A. \& Georgakopoulou, A. (2008). Analyzing narratives as practices. Qualitative Research, 8(3), 379-387.

Department of Health. (2010). Equity and excellence: Liberating the NHS. London: HMSO.

Doherty, C. \& Stavropoulou, C. (2012). Patients' willingness and ability to participate actively in the reduction of clinical errors: A systematic literature review. Social Science \& Medicine, 75, 257-263. Edmonson, A.C. (2003). Speaking Up in the Operating Room: How Team Leaders Promote Learning in Interdisciplinary Action Teams. Journal of Management Studies, 40(6), 1419-1452.

Fear, W.J. (2013) What is the story? The uniqueness paradox and the Patient Story in the minutes of the boardroom. Management Learning, 0(0), 1-15.

Fisher, W. (1984). Narration as a human communication paradigm: the case of public moral argument. Communication Monographs, 51, 1-22.

Frank, A.W. (1997). The Wounded Storyteller. Chicago: The University of Chicago Press. Frank, A. W. (2000). The standpoint of storyteller. Qualitative Health Research, 10, 354-65. Gabriel, Y. (1999). The use of stories. In C. Cassell and G. Symon (eds.) Qualitative Methods and Analysis in Organizational Research: A practical guide. London: SAGE.

Geertz, C. (1973). Interpretation of cultures. New York: Basic Books.

Green, S.E. \& Li, Y. (2011). Rhetorical Institutionalism: Language, Agency and Structure in Institutional Theory since Alvesson 1993. Journal of Management Studies, 48(7), 1662-1697. Greenhalgh, T., Russell, J. \& Swinglehurst, D. (2005). Narrative Methods in Improvement Research. Quality and Safety in Health Care, 14(6), 443-449

Hales, C.P. (2007). Structural Contradiction and Sense-Making in the First-Line Manager Role. Irish Journal of Management, 28(1),147-179.

Healthcare Commission. (2006). Investigation into Mid-Cheshire NHS Hospitals Trust. Commission for Healthcare Audit and Inspection.

Healthcare Commission. (2007). Investigation into outbreaks of Clostridium difficile at Maidstone and Tunbridge Wells NHS Trust. Commission for Healthcare Audit and Inspection. Healthcare Commission. (2009). Investigation into Mid-Staffordshire NHS Foundation Trust. Commission for Healthcare Audit and Inspection. 
Hor, S., Godbold, A. \& Iedema, R. (2013). Finding the Patient in Patient Safety. Health 0(0), 1-17. Hudson, P. (2003). Applying the lessons of high risk industries to health care Quality and Safety in Health Care, 12(suppl), i17-i12.

Iedema, R. (2009). New approaches to researching patient safety. Social Science and Medicine, 69, $1701-1704$.

Iedema, R. (2011). Discourse studies in the 21st century: A response to Mats Alvesson and Dan Kärreman's 'Decolonializing discourse'. Human Relations, 64, 1163-1176.

Iedema, R., Jorm, C. \& Lum, M. (2009). Affect is central to patient safety: The horror stories of young anaesthetists. Social Science \& Medicine, 69, 1-7.

Iedema, R., Flabouris, A., Grant, S. \& Jorm, C. (2006). Narrativizing errors of care: Critical incident reporting in clinical practice. Social Science \& Medicine 62, 134-144.

Islam, G. \& Zyphur, M. (2007). Ways of interacting: The standardization of communication in medical training. Human Relations, 60(5), 769-792

JCAHO (2011). Speak Up Initiatives. The Joint Commission website.

http://www.youtube.com/user/TheJointCommission accessed 6th Nov 2012.

Jorm C. M., Dunbar N., Sudano L. \& Travaglia J. F. (2009). Should patient safety be more patient centred? Australian Health Review 33(3), 390-399.

Klein, R. (2006). The New Politics of the NHS ( $5^{\text {th }}$ edn). Radcliffe Publishing Ltd: UK.

Kramer, R. (1999). Trust and Distrust: Emerging Questions, Enduring Questions. Annual Review of Psychology, 50, 569-91.

Labov, W. (1997). Some further steps in narrative analysis. Journal of Narrative and Life History, $7(1-4), 395-415$.

Lloyd, A.J. (1991). The extent of patients' understanding of the risk of treatment. Quality in Health Care,10(suppl I):i14-i18.

Lukes, S. (2005). Power: A Radical View (2 ${ }^{\text {nd }}$ edn). Basingstoke: Palgrave Macmillan.

Maitlis, S. (2005). The social processes of organizational sensemaking. Academy of Management Journal, 48(1), 21-49. 
Maitlis, S. \& Lawrence, T.B. (2007). Triggers and enablers of sensegiving in organizations. Academy of Management Journal, 50(1), 57-84.

Mayer, R.C., Davis, J.H. \& Schoorman, F.D. (1995). An Integrative Model of Organizational Trust, Academy of Management Review, 20(3), 709-34.

Meyerson, D., Weick, K. E. \& Kramer, R. M. (1996). Swift Trust in Temporary Groups, In R. M. Kramer, R. M. \& Tyler, T. R. (eds) Trust in Organizations: Frontiers of Theory and Research. Thousand Oaks, CA: SAGE, 166-195.

Munro, I. \& Huber, C. (2012). Kafka's mythology: Organization, bureaucracy and the limits of sensemaking. Human Relations, 65(4): 523-540.

Neuberger, J. (1999). The NHS as a theological institution. British Medical Journal,18; 319(7225): $1588-1589$.

Ocloo, J. E. (2010). Harmed patients gaining voice: challenging dominant perspectives in the construction of medical harm and patient safety reforms. Social Science \& Medicine, 7(3), 510-516. Patton, M.Q. (2002). Qualitative Research and Evaluation Methods ( $3^{\text {rd }}$ edn). Thousand Oaks, CA: Sage.

Reason, J. (2008). The Human Contribution Unsafe Acts, Accidents and Heroic Recoveries. Ashgate Publishing Ltd: England.

Riessman, C.K. (1993). Narrative Analysis. London: SAGE.

Saunders, M.N.K. (2012). Choosing research participants. In Cassell, C., and Symon, G., (eds) The Practice of Qualitative Organizational Research: Core Methods and Current Challenges. London: SAGE, 37-55.

Syrjälä, J., Takala, T. \& Sintonen, T. (2009). Narratives as a tool to study personnel wellbeing in corporate mergers. Qualitative Research, 9(3), 263-284.

The Information Centre (2010). available at www.ic.nhs.uk Vickers, D. (2008). Beyond the hegemonic narrative -a study of managers. Journal of Change Management, 21(5), 560-573.

Waring, J. J. (2009). Constructing and re-constructing narratives of patient safety. Social Science \& Medicine, 69, 1722-1731. 
Weick, K.E. (1988). Enacted Sensemaking in Crisis Situations. Journal of Management Studies, 25(4), 305-317.

Weick, K.E. (1993). The Collapse of Sensemaking: the Mann Gulch disaster. Administrative Science Quarterly, 38(4), 628-652.

Weick, K.E. (1995). Sensemaking in Organizations. London: SAGE.

Weick, K.E. \& Browning, L.D. (1986). Argumentation and Narration in Organizational

Communication. Yearly Review of Management of the Journal of Management, 12(2), 243-259.

Weick, K.E. \& Sutcliffe, K.M. (2003). Hospitals as cultures of entrapment: A reanalysis of the Bristol Royal Infirmary. California Management Review, 45(2), 73-85.

Weick, K.E., Sutcliffe, K.M. \& Obstfeld, D. (2005). Organizing and the process of sensemaking. Organization Science, 16(4), 409-421.

Williams, S. J. \& Calnan, M. (1996). The 'limits' of medicalization?: Modern medicine and the lay populace in 'late modernity' Social Science \& Medicine, 42(12), 1609-1620. 